\title{
La política repobladora del reinado de Carlos II
}

\author{
Juan A. Sánchez Belén *
}

Entre los varios asuntos que acapararon el interés de los Habsburgo, especialmente a partir de finales del siglo XVI, hay que destacar el de la despoblación progresiva de Castilla. Para atajar este fenómeno, visible ya en las Relaciones Topográficas de Felipe II, el 30 de octubre de 1622 , su nieto, Felipe IV, en carta dirigida a las ciudades, previo informe de la Junta Grande de Reformación, establecerá una serie de normas que van desde limitar o impedir la salida de emigrantes españoles, comprendidos los que tienen su destino en América ', hasta conceder privilegios fiscales a los recién casados, a los padres de seis o más hijos varones y a los artesanos extranjeros que deseasen avecindarse con sus familias. Estas disposiciones, sin embargo, no fueron demasiado eficaces, sobre todo las últimas, porque las empresas exteriores agotaron en breve tiempo los recursos financieros de la Corona y, sin éstos, no pudieron consolidarse. Ello explica, por ejemplo, las dificultades que tuvo la Junta de Población y Comercio, instaurada en 1625 bajo la presidencia del conde-duque de Olivares, para retener a seiscientos artífices de origen valón afincados en Arévalo y que en 1629 habian puesto en funcionamiento setenta y cuatro telares, toda vez que las Cortes rehusaron otorgar los fondos necesarios que garantizaban su supervivencia ${ }^{2}$.

* Profesor titular de Historia Moderna. UNED.

- Según MÓRner, Magnus, la emigración hacia América descendió de 111.312 personas en el período $1601-1625$ a 83.504 entre 1626 y 1650, lo cual nos permite hacernos una idea del impacto de las medidas restrictivas aplicadas por la Corona para atajar este fenómeno y del bache demográfico de Castilla en el segundo cuarto del siglo xVII. Ver "La emigración española al Nuevo Mundo antes de 1810. Un informe del estado de la investigación", Anuario de Estudios Americanos, XXXII, Sevilla, 1975, págs. 43-131.

${ }^{2}$ Eluior, J. H., The Count-Duke of Olivares. The States man in an Age of Decline. New Haven and London, 1986, pág. 414; “El programa de Olivares y los movimientos de 1640", en La España de Felipe IV. El gobierno de la Monarquía, la crisis de 1640 y el tracaso de la hegemonía española. Madrid 1982, págs. 351-52. 
Desde sus inicios, los gobiernos sucesivos de Carlos II afrontaron esta materia con mayor o menor energía, coincidiendo sus soluciones muy a menudo con las postuladas por los arbitristas. Es cierto, no obstante, que no se emprendió un programa repoblador como el que se ejecutará en la época de Carlos III pero aun así es preciso resaltar que se buscó frenar la huida de los pueblos, favoreciéndose incluso el asentamiento de familias en lugares abandonados. No tiene entonces razón el hispanista J. H. Elliott cuando afirma que tras la caida de Olivares ningún ministro se atrevió a embarcarse en reformas tan radicales como las suyas y menos todavia en que el fracaso de su proyecto político paralizó toda actividad hasta la llegada al poder de los Borbones. La credibilidad de estas opiniones se resiente de manera notable a poco que consultemos la documentación conservada en nuestros archivos ${ }^{3}$.

Aunque la mayoria de los arbitristas juzgaba que la despoblación del Reino era un hecho incuestionable - sólo Francisco Centani contradirá esta creencia en $1671^{4}$-, se imponía realizar en Castilla un vencindario, con inclusión de la riqueza de sus habitantes, para que la Corona, disponiendo de datos fidedignos, pudiese diseñar de forma racional sus planes de saneamiento económico. Esta exigencia, formulada en 1666 por Diego Felipe de Albornoz, retomada en 1669 por Alejandro Parenti y Manuel Mayers, encuentra su expresión máxima en el Zelador General, escrito por Alvarez Osorio y Redín en los años ochenta -recordemos que hasta 1682 no concluyó la epidemia iniciada a finales de los setenta procedente del Levante-:

«Se servirá V. M. de mandar por su Real Decreto que se haga suma general de todas las matrículas de parroquias en todos los reinos y señorios, poniendo por pie de lista todas las personas de los lugares,

${ }^{3}$ Elltom, J. H., The Count-Duke..., pág. 676, y «Poder y propaganda en la España de Felipe IV", en Homenaje a José Antonio Maravall, t. I. Madrid 1985, pág. 42

${ }^{4}$ Centani, F., Tierras, Medios universales propuestos desde el año de seiscientos y sesenta y cinco hasta el seiscientos y setenta y uno, para que con planta, número, peso y medida tenga la Real Hacienda dotación fija para asistir a la Causa Pública, remedio y alivio general para los pobres, cortando fraudes de que han hecho patrimonio los que to dominan. Madrid, 16 de junio de 1671, BNM. Varios especiales (VE), 69/54, fol 287. 
con distinción de los estados y oficios de cada uno. Con esta lista se sabrá las personas que se necesitan en cada lugar para todo género de artes y para defender las fronteras y guarnecer los ejércitos y armadas. Porque si no se proporcionan las partes de que se compone el todo de esta Monarquía, continuamente se hallará imperfecta por falta de mensuración en todas su dimensiones" ${ }^{5}$.

Muchos ayuntamientos de Castilla se pronunciaron también en este sentido, según se desprende del contenido de sus memoriales, ya que en buena medida sus agobios económicos no radicaban tanto en la multiplicidad de tributos que debían abonar como en su desigual reparto, por distribuirse de acuerdo con las cifras del censo de 1590-1591, sin que los contadores tuviesen en cuenta los cambios operados desde esta fecha en la evolución demográfica de los lugares, habiendo aumentado en unos su vecindario y disminuido en otros por un complejo entramado de reveses naturales y de acontecimientos políticos y militares adversos. De este modo, el concejo de Castronuño solicita en 1665 que el importe del servicio real se adapte a "la vecindad que hoy tiene, sin que se le obligue a que pague más" ${ }^{6}$. Análoga demanda formulan en 1669 Villalpando y Becerril de Campos ${ }^{7}$ y en 1677 Aranzueque, para quien "las cargas de sisas y unos por cientos que está pagando la tienen a pique de despoblarse, porque al presente no se halla más que con cuarenta vecinos y diez pares de labor y muchas más carga que la antigua" ${ }^{8}$. A partir de 1685 un número considerable de poblaciones de Toledo y La Mancha representan la misma queja tras la epidemia de tifus y las malas cosechas de los años precedentes. Así, Almonacid no duda en exponer al Consejo de Hacienda que sus débitos del período 1683-1685 proceden de su despoblación, pues "los más han muerto y ausentado y otros han venido a tal miseria [...] que se hallan pobres de solemnidad" ${ }^{9}$. Por su parte, Casarrubios de Monte denuncia cómo, sin embargo de haber perdido la mitad de sus vecinos, continúa pagando "los repartimientos en las mismas cantidades que en tiempos antiguos, continuándose los en-

5 Alvarez Osorio y Redin, M., Zelador General para el bien común de estos Reinos... BNM, Mss. 6659, fol. 171 v; Albornoz, F., Castilla politica y cristina. Madrid 1666, fols. 81v82v; MAYERS, M., Memorial a la Reina Nuestra Señora, en que se da modo y forma para quitar los tributos sin menoscabo de la Real Hacienda y con alivio general de los vasallos, 1669. BNM, Mss. 6579 y VE, 47/34, fol. 2; PARENTI, A., Breve recopilación del remedio y alivio de esta Monarquía de España y más conocido senvicio y desempeño de Su Majestad, que Dios guarde. AHN, Consejos Suprimidos, leg. 9.179, exp. 98, fol 3.

6 AGS, Contadurias Generales, leg. 748.

7 lbidem, leg. 748 y 749 .

${ }^{8}$ Ibídem, legs. 696 y 753.

9 AGS, Consejo y Juntas de Hacienda, leg. 1.516. 
cabezamientos a los excesivos precios que estaban antes de la baja de la moneda" ${ }^{10}$. Ésta es también la causa de que Altarejo, según reconoce el contador de millones de Cuenca, se vaya despoblando a un ritmo acelerado por no poder sus vecinos "sobrellevar los muchos y considerables tributos que se le cargaba" ". Hacia 1697 la situación ha cambiado poco, pues Archidona justifica su despoblación y el crecimiento de Antequera por el trasiado hacia esta ciudad de sus vecinos "huyendo de los repartimientos" ${ }^{12}$, fenómeno observable asimismo en Provencio, como constata el superintendente de Cuenca ${ }^{13}$.

Algunos ministros $\mathrm{e}$ instituciones no permanecieron ajenos a este requerimiento. En 1667, una Junta de Medios, de la que formaba parte el confesor de doña Mariana de Austria, el padre Nithard, juzgó imprescindible confeccionar un recuento de familias para después regular lo que cada una debía contribuir al tesoro. La negativa del valido, ante el temor, seguramente fundado, de que su ejecución dilataría la reforma fiscal que patrocinaba, relega al olvido dicho proyecto hasta la mayoría de edad del monarca ${ }^{14}$. Durante el gobierno de don Juan José asistimos a un nuevo intento por conocer la población y riqueza del Reino. El 15 de enero de 1678, el Consejo de Castilla despacha una provisión a las justicias locales en la que se les ordena averiguar los recursos económicos de los pueblos y sus expectativas de progreso -es de suponer que también sus efectivos humanos-, con el objetivo de que "se introduzgan [...] los tratos y granjerias que parecieren más convenientes según el estado y disposición de los vecinos y de los lugares y calidad de la tierra" ${ }^{15}$. Meses más tarde, una Real Cédula requiere de los corregidores informes de los despoblados que hay en sus respectivas jurisdicciones y de la gente que se necesita para restituirlos a su estado anterior, asi como de las personas que estarían dispuestas a trasladarse a ellos desde las zonas superpobladas del norte: Burgos, Vizcaya, León, Asturias y Galicia ${ }^{16}$.

${ }^{10}$ AHN, Consejos, leg. 7.198, exp. 20.

$"$ AGS, Cont. Gles., leg. 753.

12 AGS, CJH, leg. 1.666. Consulta del Consejo de Hacienda, 8 de junio de 1697.

13 Ibídem. Consulta del Consejo de Hacienda, 23 de mayo de 16797.

14 Citado por Matilla TASCÓN, A., La única contribución y el Catastro de Ensenada. Madrid 1947, pág. 22.

${ }^{15}$ BNM, mss. 4466. Provisión del Consejo de Castilla, 15 de enero de 1678. Menciona este documento Danvila y Collado, M., El poder civil en España, t. Ili. Madrid 1895, página 238, y Kamen, H., La España de Carlos II. Barcelona 1980, pág. 58.

${ }_{16}$ AHN, Consejos, lib. 1.474, ex. 14, y 1.510, ex. 7. Los citan también DanviLA y CoLLADO, M., obra citada, t. III, pág. 219, y Gil-Ayuso, F., Noticia bibliográfica de textos y disposiciones legales de los Reinos de Castilla impresos en los siglos XVI y XVII. Madrid 
Con independencia de que no hemos conseguido localizar los informes solicitados y ni tan siquiera la correspondencia que por este motivo se hubiese intercambiado entre los corregidores y el Consejo de Castilla - de ello se lamenta Henry Kamen ${ }^{17}$-, ningún indicio nos permite suponer que ambos planes llegaran a materializarse. Que esto es asi lo confirma la Instrucción de 1682, pues uno de sus capítulos encarga a los superintendentes provinciales comisionados para el ajuste del encabezamiento general del Reino elaborar padrones de vecinos de cada lugar, donde consten además los exentos y sus actividades productivas, y si son o no consumidores de lo que producen ${ }^{18}$. La lentitud con que se encabezaron los pueblos, imputable casi siempre a la reticencia de sus concejos en admitir los valores que se les asignaban, fue un factor decisivo para que la Junta responsable de la gestión de estos funcionarios les eximiera del cumplimiento riguroso de dichos padrones, a pesar de que determinados informes contenían datos valiosos sobre la materia, como los elaborados por don Pedro Velluti de Haro, superintendente de Soria ${ }^{19}$. Esta es la razón por la cual ocho años más tarde se les vuelve a encomendar que indaguen "el estado en que se halla cada lugar [...], los vecinos de que se compone, sus tratos y granjerías", todo con el propósito de evitar repartos injustos de la carga fiscal y erradicar "las perniciosas consecuencias de los ociosos y vagabundos", logrando al mismo tiempo «la utilidad y beneficio de la causa pública y más contribuyentes en aumento de las rentas reales" ${ }^{20}$. Habrá que esperar, sin

\section{5, página 330 .}

No parece muy desajustada la idea de un crecimiento demográfico en el norte peninsular, al menos no para el caso asturiano. Ver Sanzo Fernández, M. ${ }^{a}$ Carmen, "La población de Asturias en los siglos XVII a XIX: Los registros parroquiales". La economía española al final del Antiguo Régimen. I. Agricultura. Madrid, ed. Gonzalo Anes, 1982, págs. 261-348. Lo propio se puede decir de Galicia y las provincias vascas, pero ya no es tan seguro para Burgos y menos aún para León. Ver NADAL, J., La población española (siglos XVI a XIX). Barcelona 1984, págs. 77-84.

17 KAMEN, H., obra citada, págs. 58 y 302. Sólo hemos localizado un escrito en respuesta a la provisión y Real Cédula de 1678 pero está fechado en 1680: el memorial de Diez de Noreña cuyo título reza así: Respuesta política, moral, histórica y legal de dos Cédulas Reales y provisión del Supremo Consejo de Castilla, BNM, Mss. 4466. Esperamos que la profesora Josefina Castilla Soto tenga mejor fortuna en sus investigaciones sobre don Juan José de Austria.

18 AGS, CJH, leg. 1966. El artículo a que nos referimos, el número 18, dice asi: "Haréis numeración de los vecinos de cada lugar, declarando los exentos, y reconoceréis los tratos, labores y granjerías que tienen, si es lugar de frutos o de sólo consumo, y de todo se ha de formar relación con entera claridad".

${ }_{19}$ Para mayor información, ver mi articulo "Absolutismo y fiscalidad en Castilla a fines del siglo XVII: El encabezamiento general del Reino, 1682-1685", Espacio, Tiempo y Forma, serie IV, número 2, Madrid 1989.

20 AGS, Dirección General del Tesoro, Inve. 24, leg. 647. 
embargo, a 1693-1694 para que el Estado disponga de un cálculo aprovechable de la población castellana, si bien su validez en orden al estudio de la demografía es muy cuestionado por tratarse de un recuento elaborado con ocasión de una leva de soldados, y aun así tampoco parece que se aplicara en futuros encabezamientos ${ }^{21}$.

La ausencia de un censo general de Castilla como el efectuado en 1590 1591 va a impedir que los contadores de Hacienda puedan contrastar las cifras de vecinos alegadas por los pueblos en sus memoriales para reclamar menos contribuciones - con cierta frecuencia el Consejo ordenará a los corregidores, superintendentes o administradores que comprueben su veracidad in situ- y, por tanto, actualizar los impuestos que se les reparten según sus disponibilidades o, cuando lo aconsejaban las circunstancias, suspender su cobro de forma permanente.

Tal vez convenga minimizar o situar en su justo alcance el impacto negativo de los tributos en el desarrollo demográfico y económico del país, pero mientras no dispongamos de estudios locales y regionales donde quede reflejado este fenómeno con nitidez, tendremos que aceptar, eso sí, con cautela, los testimonios coetáneos - Pérez Moreda, por ejemplo, nos pone en guardia acerca del contenido de muchos memoriales enviados por los concejos, no siempre fidedigno ${ }^{22}$ - . Sea como fuere, hay que admitir sin ambages los perjuicios que puede originar una fiscalidad desproporcionada respecto a la riqueza de los súbditos en una sociedad con evidentes síntomas de estancamiento, si no de crisis, por cuanto incide en los costes de producción reduciendo los beneficios netos, muy mermados ya por otros

${ }^{21}$ AGS, Guerra Antigua, legs. 2933 y 2934 . Un estudio crítico de esta fuente y de otras del antiguo Régimen, en MARTín GaLAN, M., "Fuentes y métodos para el estudio de la demografía histórico-castellana durante la Edad Modernaw, Hispania, XLI. Madrid 1981, págs. 247-248. Admite la validez de esta fuente en términos generales. LOPEZ-SALAZAR PÉREZ, J.: “Evolución demográfica de La Mancha en el siglo XVIII", Hispania, XXXVI, Madrid (1976), págs. 233-299, y "La población manchega en los siglos XVI y XVII", Revista Internacional de Sociologia, XXXIX. Madrid, núms. 37 y 38 (1981), págs. 7-31 y 191-231. Garcia SANZ, Angel, por el contrario, la desestima: Desarrollo y crisis del Antiguo Régimen en Castilla la Vieja. Economía y sociedad en tierras de Segovia, 1500-1814. Madrid 1977. Lo mismo hace Fortea Perez, J. l.: Fiscalidad en Córdoba. Fisco, economía y sociedad: alcabalas y encabezamientos en tierras de Córdoba (1513-1619). Córdoba 1986, pág. 53. 1980.

${ }^{22}$ Perez Moreda V., Las crisis de mortalidad en la España interior (siglos XVI-XIX), Madrid 
gravámenes no menos onerosos, con lo que se favorece la despoblación de los lugares y el afincamiento de sus vecinos en ciudades con posibilidades de medro. Como escribe el licenciado José Calero Gallego en 1667, «el que apenas se puede sustentar en su patria procura buscar el consuelo y remedio en la ajena, donde las cargas sean más ligeras y donde no esté expuesto a las injurias y extorsiones de los cobradores y exactores de tributos" ${ }^{23}$. En 1671, Francisco Centani sostiene también que si se moderan los impuestos descenderán los costes y, en consecuencia, aumentarán los rendimientos agrícolas, incentivando el matrimonio de labradores jóvenes, «pues al presente muchos no casan por la dificultad que hay en buscar el sustento, y estando libres y sin carga tendrán precio tan acomodado que con mediana aplicación podrán vivir y al mismo tiempo que vaya creciendo por este camino el estado secular" ${ }^{24}$.

En la década de los ochenta, el ataque contra los impuestos arrecia entre los arbitristas, sobre todo porque todavía no se han superado los efectos de la reforma monetaria decretada en 1680 y que coincide con las secuelas últimas de la pandemia de fines de los setenta, a la que seguirá una sucesión de malas cosechas y una nueva epidemia, con toda probabilidad tifus, en Toledo y La Mancha, principalmente ${ }^{25}$. Así, Díez de Noreña manifiesta en dicho año que los tributos son la causa fundamental que explica el proceso descapitalizador del campo, la huida masiva de los pueblos y el empobrecimiento general de la sociedad, pues al desencadenar un aiza inmoderada de los precios no sólo obliga al agricultor a detraer sumas elevadas de dinero para satisfacer sus necesidades primarias, sino que encarece los salarios de los jornaleros $y$, en definitiva, revierte en el volumen de las cosechas, por tenerse que dejar erial una buena parte de la superficie cultivada ante la falta de medios para su laboreo:

"El menesteroso no come porque no lo tiene ni el rico se atreve a gastar porque no le alcanza. Todos quedan faltos de sustento y, hechos

${ }^{23}$ Calero Gallego, J., Advertencias útiles para la buena y perfecta administración de las rentas reales y alivio de los vasallos, 16 de julio de 1667, British Library, Egg, 2084, fol. 296.

${ }^{24}$ CENTANI, F., Ibídem, fols. 290-290v. Este criterio ya lo había manifestado en su memorial de 1665 (BNM, Mss. 6579, fol 9v). Otro autor que suscribe estas opiniones es SOMOZA Y QuIROGA, A., Unico alivio de los vasallos de la Corona de Castilla: expulsión de escusados ministros y particular aumento del Real Patrimonio tocante a la segura moderación y baxa de millones... Madrid, septiembre 1677.

${ }_{25}$ Sobre estos efectos, Kamen, H., obra citada, págs, 78-98; Pérez MOREda, V., obra citada, páginas 303 y ss, y Dominguez Ortiz, A., "La crisis de Castilla en 1677-1687», en Crisis y decadencia en la España de los Austrias. Barcelona 1969, págs. 195-217. KAMEN, $\mathrm{H}$., ya nos habia anticipado algo en su articulo "The Decline of Castile: The Last Crisis", Economic History Review, I, núm. 17 (1964), págs. 63-76. 
una confusión pecaminosa, acaban con las vidas porque no alientan los cuerpos con apropiados manjares, con las haciendas si han de cubrir sus carnes aun con la menor decencia” ${ }^{26}$.

En 1681, Gavi y Cataneo, en su proyecto de un impuesto único, resalta entre sus beneficios la libertad de comercio, principio clave a su juicio para el florecimiento de la actividad agrícola e industrial de los pueblos y del nivel de vida de sus habitantes, permitiéndoles sustraerse de las epidemias, ya que éstas tienen su origen en la desnutrición provocada por la carestía y escasez de dinero para alimentarse convenientemente, sobre todo en épocas de malas cosechas ${ }^{27}$. En 1685, José de la Serna Cantoral, en nombre de la ciudad de Salamanca, tras aprobar la prórroga del servicio de millones por un sesenio más, denuncia el efecto pernicioso de las alcabalas y cientos en la economía y la demografía del Reino, pues por esta causa "falta el cariño con los hijos y mujeres y se entibia la propagación porque mira con horror a los que le sirven de carga, sin tener materia para alimentarles. Dejan sus cortas haciendas porque las tienen todas cargadas de censos, y [...], por último, sólo les falta el no faltar del todo" ${ }^{28}$. Esta descripción, pincelada con tintes sombríos, sin duda con el ánimo de resaltar la buena acogida que tienen los deseos del soberano pese a las adversidades que padece la ciudad, la encontramos asimismo, con escasas variantes, en los votos de los señores Antonio Monsalve y Andrés de Herrera, caballeros veinticuatro de Sevilla, quienes llegan al extremo de asegurar que la miseria de los vasallos les impulsa a dejar abandonados sus hijos en las puertas de la ciudad o en los zaguanes de las casas pudientes, en tanto los hombres se dedican a pedir limosna y las mujeres a prostituirse «en todas edades para poder apenas alimentarse" ${ }^{29}$. En 1700 insiste en el tema el patriarca de las Indias, don Pedro Portocarrero, cuando advierte al archiduque Carlos sobre los peligros que engendra la miseria por causa de los tributos:

26 Diez de Noreña, R., obra citada, fol. $14 \mathrm{~V}$.

27 GAVI Y CATANEO, J., Tratado en orden a una general reforma de millones, así para el mayor servicio de Su Majestad y mayor utilidad de su Real Hacienda, como para universal alivio de los vasallos todos... Granada 1681, fols. 12, 15-15v y 16.

28 De la Serna Cantoral, J., Si la prorrogación de millones de que la Majestad del Señor Rey Carlos II, N. S., ha pedido consentimiento a la ciudad de Salamanca este año de 1685 se debe conceder en la proporción y estado del tiempo..., 9 de febrero de 1685, fols. 6-6v.

${ }^{29}$ BNM, Mss. 18643/58. 
«La pobreza es la mayor de todas las indignidades [...] Si el vasallo la padece desampara su familia y ésta, huérfana, se pierde por falta de educación o aplicación al trabajo [...] Despuéblanse los lugares, los campos no se cultivan porque importan más los impuestos sobre sus frutos que el útil que al labrador le deja el penoso afán de su cultura, de que proviene la riqueza del Reino. Y sí ésta falta, todo falta» ${ }^{30}$.

\section{III}

Los testimonios que acabamos de reseñar plantean con desgarro y sin ambigüedad que la solución de la crisis agrícola, industrial y comercial de Castilla a fines de la centuria depende de la supresión de los tributos o, por lo menos, de su moderación. Si éstos son suaves y ajustados a la capacidad contributiva de los súbditos, su progreso estará asegurado y también el incremento de los efectivos humanos, lo que redundará en beneficios mayores para la Real Hacienda sin tener que recurrir a devaluaciones monetarias ni verse en el imperativo de empeñar las rentas, aparte de que se incentivará el asentamiento de artesanos extranjeros, pues, en palabras de Espinosa Velarde, éstos, al ver disminuir sus ganancias por la competencia de las manufacturas españolas, y uno teniendo en sus tierras qué trabajar, les sucederá lo que nos sucede [...], que obligados de la necesidad buscarán donde hallen quehacer en sus oficios" ${ }^{31}$.

Estas opiniones, junto con las expuestas por los pueblos en sus memoriales, no serán desestimadas por la Corona, convencida de que el hombre "es el árbol más fructífero que tiene el mundo", en acertada expresión de Álvarez Osorio ${ }^{32}$. Dejando al margen una serie de reformas en el gobierno de las rentas provinciales y en la recuperación del patrimonio enajenado por el rey, de las que daremos cumplida noticia en un libro próximo a publicarse, y del reajuste monetario de 1680-86, que cuenta con algunos trabajos meritorios, como el de Merino Navarro y

30 Portocarrero, P., Theatro Monarchico de España que contiene las más puras como cathólicas máximas de Estado, por las cuales asi los príncipes como las repúblicas aumentan y mantienen sus dominios, y las cuasas que motivan su ruina... Madrid 1700. Discurso II, fols. 134-135.

31 Espinosa Velarde, F. DE, Sacra y Católica Real Majestad..., BNM, V.E., 209/129, fols. $1 \mathrm{~V}-2$.

32 Álvarez Osorio M., obra citada, $174 \mathrm{v}$. 
Collantes Pérez-Ardá ${ }^{33}$, los ministros de Carlos II, desde el desprestigiado padre Nithard hasta el ensalzado conde de Oropesa, van a emprender una sistemática reducción en el valor nominal de los impuestos, proporcionándole a la capacidad tributaria de los pueblos, cuando no suspendiendo su cobro por un período de tiempo más o menos prolongado, o condonando parte de las deudas.

La abolición del servicio de quiebra de millones, decretada en 1669 aunque ya había sido aprobada a finales de 1668, sin duda por iniciativa del padre Nithard, es un paso importante en esta política de moderación tributaria que se persigue y a la que responden asimismo, a instancias de la Junta de Alivios, creada en 1669, ciertos recortes en las cuotas del servicio de milicias y el perdón de deudas atrasadas procedentes de los donativos concedidos por el Reino a Felipe IV $^{34}$. El ascenso al poder de don Juan José de Austria, no obstante su interés por mejorar el nivel económico de los súbditos, según se desprende de una consulta suya dirigida al monarca en 1663 , fecha en la que se revoca el decreto promulgado en 1661, mediante el cual quedaban exentos de contribuir al erario todas las localidades comprendidas en un radio de cinco leguas de la frontera con Portugal, no va a suponer novedades dignas de mención en materia fiscal, en parte por el conflicto con Francia y, en parte también, por la actitud contraria a sus planes de un sector de la nobleza y de los Consejos de Castilla y de Hacienda. Aun así, el 12 de agosto de 1677, en conformidad con un Real Decreto promulgado unos dias antes, se despacha una comisión al presidente de Hacienda, el conde de Humanes, para que, una vez averiguado el estado de las ciudades, villas y lugares de las provincias, transija con ellas cualesquiera cantidades que adeuden al tesoro con anterioridad a 1673, ajustando, si es preciso, toda clase de arbitrios para facilitar su pago, dado el retraso en que se encuentra la cobranza de las rentas, originado de las necesidades de los pueblos por causa de guerras, tránsitos de soldados y alteraciones monetarias ${ }^{35}$. La orden, que se ejecutó con prontitud, no obstante las

33 Collantes Perez-Arda, E. y Merino Navarro, J. P., "Alteraciones al sistema monetario de Castilla durante el reinado de Carlos II", Cuadernos de investigación Histórica, Madrid, 1 (1977), pág. 73-98.

${ }^{34}$ SANCHez BelEN, J. A., "La Junta de Alivios de 1669 y las primeras reformas de la regencia", Espacio, tiempo y forma. Madrid, 4 (1989), págs. 639-667.

${ }_{35}$ AGS, $C J H$, leg. 1.607. Comisión para que transija los débitos atrasados de todas las rentas, servicios y derechos en que contribuyen las ciudades, villas y lugares del Reino de años atrasados hasta fin del de 1673 ... Esta misma Cédula de Comisión se localiza en los legajos 1.368 y 1.393 y en el libro 296, con fecha de 14 de agosto de 1677 y en la que aparece la data de la orden en 7 de agosto de 1677.

Sobre el pensamiento político de Juan José de Austria en los primeros años de la regencia, ver mi artículo ya citado en la nota 34 . 
dificultades prácticas que conllevaba su aplicación, favoreció, entre otros lugares, a Bienservida, Corilla, Raspar, Villaverde y Villapalacios, en la provincia de Jaén - los descuentos oscilaron en torno a un 52 y un 86 por 100-; a Pedroñeras, en el partido de San Clemente - se le perdona algo más del 50 por 100 de sus deudas, cifradas desde 1651 en 7.494.322 mrs.--; a Jerez de los Caballeros - se le condona un 74 por $100-$, y a la ciudad de Almagro y su tierra, deudores nada menos que de $10.862 .481 \mathrm{mrs}$. por alcabalas, cientos y servicio real -la cantidad que ahora deben pagar se minora a tan sólo cuatro millones- ${ }^{36}$.

En 1680, a raíz de la alteración sufrida en los precios por la reforma monetaria, se procede a cancelar en todo el Reino parte de sus deudas, evaluadas en 4.488 cuentos de maravedís (unos doce millones de ducados), hasta 1673 -esto supone que el decreto de 1677 no incidió en la totalidad de los pueblos- ${ }^{37}$. Dos años después, durante el encabezamiento general, se emprende una vez más este recurso, así como una rebaja sustancial en los valores nominales de las alcabalas, cientos y millones, cifrada en un 18 por 100 , aunque algunas provincias apenas se beneficiaron - es el caso de Madrid, que ve rebajado su encabezamiento en un 2 por $100-y$ otras consiguieron descuentos comprendidos entre el 30 y el 50 por 100 , como Córdoba ${ }^{38}$.

En 1685, ante la situación alarmante del Reino, el Consejo de Hacienda expone al monarca que está discurriendo con la mayor aplicación «la forma que generalmente se podrá dar para que los tributos [...] sean suaves y puedan cobrarse con mayor conveniencia de los contribuyentes", toda vez que así se logrará "el alivio de las villas y lugares para que las vecindades que al presente han quedado se conserven en sus domicilios, cultiven sus haciendas, beneficien los frutos que produjeren, ejerciten sus tratos y comercios y pueda mejor servir y contribuir en los repartimientos" ${ }^{39}$. El resultado de estas deliberaciones se materializará en la suspensión en 1686 de los recargos añadidos al servicio de millones en tiempos de Felipe IV y en la rebaja a la mitad de los cientos. Simultáneamente, se autoriza a los administradores y superintendentes transigir las deudas de los pueblos, quedando excluidos aquellos que obtuvieron dicho alivio en 1685 . Por este motivo se otorgaron descuentos

${ }^{36}$ Ibidem, leg. 1.369. Informe de don Andrés de Villarán, 26 de noviembre de 1977, legajo 1.393. Real Cédula de 18 de febrero de 1679, leg. 1.395. Real Cédula de 20 de mayo de 1679, leg. 1.397. Real Cédula de 26 de noviembre de 1678.

37 Ibídem, leg 1.407. Pragmática de 10 de febrero 1680 e Instrucción que se ha de guardar sobre la baja de la moneda de molino..., 10 de febrero de 1680 .

38 SÁNCHEZ BELÉn, J. A., "Absolutismo y fiscalidad...", Cuadro I.

39 AGS, $C J H$, leg. 1.481. Consulta del Consejo de Hacienda, 4 de noviembre de 1685. 
entre un 25 y un 60 por 100 según las circunstancias de cada lugar, llegándose a perdonar hasta el 73 por 100 y en casos excepcionales la totalidad de los débitos, como sucede con Fresnedilla (Segovia), Tribaldos (Toledo), Vega de Cernejo (León) y Ávila ${ }^{40}$. En 1688, a propuesta del conde de Oropesa, se anula el derecho de los pescados frescos de los ríos (otro recargo concedido por las Cortes para el pago del servicio de dos millones y medio), con lo cual se deduce que, sin derogarse el servicio de millones, como lo exigían los arbitristas, las ciudades y villas y algunos ministros -el marqués de los Vélez, por ejemplo-, su importe se vio muy reducido en estos años. Asimismo, se promulga una nueva remisión de deudas en Castilla, siempre y cuando no procedan de las justicias locales encargadas de la recaudación de los tributos ni por impagos de los fieles y depositarios ${ }^{41}$. La medida supondrá un alivio enorme para un porcentaje elevado de comunidades. La mejor prueba nos la ofrece el caso de los gremios de Valladolid, pues consiguen el perdón de $20.255 .313 \mathrm{mrs}$., comprometiéndose a pagar únicamente $5.717 .531 \mathrm{mrs}$. que pertenecen a los juristas. Poco más o menos acontece con Medina del Campo, a cuyos vecinos se les condonan 7.828.400 mrs. de un total de 14.000 .000 en que eran alcanzados ${ }^{42}$. En este año, con la finalidad de evitar su despoblación, se perdonan las deudas de Alvares (Ciudad Real), Arenzana de Arriba (Burgos), Valdecañas (Palencia) y Valdelaguna, en Segovia ${ }^{43}$.

En 1691, tras varias presiones de las ciudades, el Consejo de Hacienda sugiere, lo que es aceptado por el monarca, moderar en un tercio el repartimiento del Chapín de la Reina ${ }^{44}$, y en 1692 se decreta una vez más la remisión de parte de las sumas en que son alcanzados los pueblos, atendiendo a las "necesidades que experimentan con los accidentes que después les han sobrevenido de falta de moneda, limitadas cosechas de frutos y poca estimación de ellos" ${ }^{45}$. En 1696, pese a las críticas de un sector de los consejeros, como la formulada un año antes

${ }^{40}$ Ibídem, legs. 1.495-1.496, 1.499-1.500, 1.504, 1.509, 1.514-1.517. Diferentes consultas de los años 1686 y 1687.

${ }^{4}$ Ibídem, leg. 1.590. Real Cédula de 6 de febrero de 1688. La propuesta del Conde Oropesa, fechada el 27 de enero de dicho año, en Canga Argüelles, J., Diccionario de Hacienda, t. II. Madrid 1833-34, pág. 110.

${ }^{42}$ Ibídem, leg. 1.541. Consulta del Consejo de Hacienda, 15 de diciembre de 1688; legajo 1.656. Consulta del Consejo de Hacienda, 9 de julio de 1696, donde se menciona la remisión otorgada a Medina del Campo en 1688.

${ }^{43}$ Ibidem, leg. 1.541. Consulta del Consejo de Hacienda, 23 de julio y 22 de septiembre de 1688; leg. 1.552. Consultas de 22 de enero y 10 de noviembre de 1689 .

${ }_{44}$ Ibídem, leg. 1.590. Consulta del Consejo de Hacienda, 1 de octubre de 1691; Canga Argüelles, J., obra citada, t. I, pág. 204.

${ }^{45}$ Ibídem, leg. 1.697. Consulta del Consejo de Hacienda, 13 de febrero de 1692. 
por el marqués de Navahermosa, se vuelve a ejecutar este recurso, pero en 1698 los abusos cometidos por las justicias locales, que se niegan a pagar los valores recaudados - se excusan incluso de proceder a la cobranza de los impuestos-, con el objetivo de obligar al Estado a promulgar remisiones análogas, ponen fin a un procedimiento que, sin duda, contribuyó a mejorar el nivel de vida de los pueblos castellanos. Quizá por este motivo más que por los fraudes, que siempre se cometieron con plena noticia del Consejo de Hacienda, incapaz por otro lado de erradicarlos, es por lo que ahora dejan de concederse rebajas generales de débitos, aunque no concluyeron si se comprobaba la necesidad alegada por los concejos ${ }^{46}$.

\section{IV}

La estabilidad de la moneda y de los precios, las transformaciones acaecidas en la economía, y el cambio de la coyuntura internacional que se produce alrededor de 1680 , son factores ciertamente que nos permiten explicar el resurgir de muchas villas y lugares durante estos años, pero no debemos menospreciar o infravalorar el papel que jugó en este sentido el descenso de la fiscalidad, frenando el.éxodo de las comunidades campesinas hacia las capitales de los partidos o hacia los núcleos urbanos más relevantes en la época y en su contorno ${ }^{47}$. Para la Corona, desde luego, éste fue uno de los escasos medios con que contaba en su esfuerzo por incentivar el aumento de la población. También lo fue a la hora de facilitar el asentamiento de habitantes en los pueblos abandonados. En este caso, el arbitrio más a propósito, el mismo que, grosso modo, utilizó Felipe II para atraer familias castellanas a Granada después de la expulsión de los moriscos en 1570, y que más tarde se adoptará en las Nuevas Poblaciones del siglo XVIII, consistió en otorgar franquicias fiscales a sus nuevos moradores por un período de tiempo de cierta

${ }^{46}$ Ibídem, leg. 1.679. Consulta del Consejo de Hacienda, 25 de septiembre de 1698. En 1699, el Consejo vuelve a referir los abusos de las justicias, en este caso la de Cañaveruelos, en el partido de Huete, por haber cobrado los impuestos de los vecinos y no querer ingresar su valor en las arcas ni entregarle a los recaudadores (lbídem, legajo 1.693. Consulta de 6 de octubre de 1699).

47 Una síntesis cronológica de la recuperación de amplias zonas de Castilla, en KAMEN, H., La España..., págs. 68-78. 
duración ${ }^{48}$. En efecto, en 1666 los partidos de Alcántara, Badajoz, Cáceres y Jerez de los Caballeros, muy diezmados por su proximidad a la frontera portuguesa, obtienen exención de tributos por un trienio, de 10 que se benefician asimismo distintas localidades de otras jurisdicciones de Extremadura, como La Coronada, en Trujillo, y Esparragalejo y Hornachos, en Llerena. De hecho, y tomando como punto de referencia los cuatro 1 por 100, observamos que en Llerena estaban evaluados en 10.099.024 mrs. anuales pero sólo se recaudaron en 1666 unos 2.290 .818 mrs., en 1667 algo más del doble (4.861.517 mrs.) y en 1668 el triple $(6.318 .980 \mathrm{mrs}$.). En Plasencia, dicho tributo se cifraba en $9.160 .828 \mathrm{mrs}$. al año y se ingresó en las arcas durante este periodo un 23 por 100. En Trujillo sucedió poco más o menos: de $19.259 .980 \mathrm{mrs}$. al año se cobró un 33 por 100 en 1666-1667 y un 50 por 100 en 1668. Entre 1669 y 1677 se prorrogaron a los partidos citados las exenciones obtenidas, salvo a Jerez de los Caballeros, que pierde esta gracia en 1671 aunque en 1676 obtiene el perdón de todas sus deudas desde aquella fecha ${ }^{49}$.

El argumento que justificaba las exenciones referidas es el mismo que se expone en 1669 cuando se concede a Aljucen, en Mérida, la suspensión de sus tributos por un cuatrienio: «para que con este alivio pueda volver a poblarse" ${ }^{50}$. La inmunidad fiscal aparece perfectamente reflejada en la Real Cédula de 14 de junio de 1678 - se garantiza por un periodo de diez años a quienes estén dispuestos a residir en alguna de las poblaciones deshabitadas- ${ }^{51}$ y la encontramos de nuevo tras la crisis demográfica de 1678-1685. En este año, una resolución del Consejo de Hacienda, refrendada por el monarca, declara a la villa de San Juan de Torres, en la provincia de León, dispensada del pago de las

48 Ver, por ejemplo, Franco, Alfonso, «Repartimientos de tierras en el obispado de Almería tras la expulsión de los moriscos (1570-1578)", en Actas / Coloquio de Historia de Andaluciá, t. I, págs. 199-208, Córdoba 1980.

En cuanto a los medios ideados para el establecimiento de las Nuevas Poblaciones, ver en las Actas del II Coloquio de Historia de Andalucía la comunicación presentada por Garcia Cano, M. ${ }^{2}$ Isabel, "La Nueva Población de Fuente Palmera (1708-1835)", págs. 23964. Para más información, consultar el libro de CARo BaroJA, J., Las Nuevas Poblaciones de Sierra Morena y Andalucía. Un experimento social en tiempos de Carlos III. Madrid, 1957, y las Actas del I y II Congresos de Historia sobre Nuevas Poblaciones. Córdoba 1986 y 1988.

${ }^{49}$ Sobre estos pueblos próximos a la frontera portuguesa, ver mi comunicación «El impacto de la Guerra de Portugal en la hacienda castellana", Actas I Jornadas de Historia Moderna. Lisboa 1989, t. I, págs. 379-394.

50 AGS, CJH, leg. 1.250 y 1.264. Consulta del Consejo de Hacienda, 23 de febrero de 1669; Cont. Gles., leg. 749. Real Cédula de 25 de marzo de 1669.

${ }^{51}$ Supra, nota 16. 
alcabalas, unos por ciento y servicio real con el propósito de alentar a los vecinos de los alrededores a establecerse en ella, por componerse de cinco familias y de un sacerdote -en 1680 ascendian a treinta y seis-, y por ser su tierra excelente para toda clase de cultivos ${ }^{52}$. En 1687, un informe aseguraba que Arroyo, Castrobol, Ebas y Villanueva de los Infantes se habían despoblado por completo, si bien, como algunos individuos de los contornos deseaban «irse [a] habitar [a] aquel lugar» - se refiere a Villanueva de los Infantes-, dada la calidad de sus términos para la agricultura y la ganadería, se resuelve eximir de tributos a dichas localidades ${ }^{53}$. Idéntico criterio se adopta un año después con Utiel, pues, según admite el Consejo de Hacienda, sus vecinos «desamparando sus casas y haciendas se habian ido a vivir con sus familias al reino de Valencia, y los que habían quedado daban muestras de hacer lo mismo" ${ }^{54}$. En 1689 se declaran eximidos del pago de sus alcabalas y cientos por dos años a los pueblos de la Merindad de la Bureba, y en 1692, por un quinquenio - se les perdona además la mitad de sus débitos-, a los concejos y lugares del valle de Valdáliga, en Santander ${ }^{55}$. En 1697, ante el grave deterioro de Vadillo, cuyos habitantes se trasladan a Cabezuela y otros lugares próximos, no obstante las diligencias del superintendente para que los alcaldes no los admitan, se le condonan sus alcances y se le exime de sus alcabalas y cientos por seis años, rebajándose el encabezamiento de millones en un 33 por $100^{56}$. Lo propio acontece con Caracena, en Cuenca, por un cuatrienio, a pesar del beneficio que obtendrán el marqués de Caracena y el conde de La Ventosa, propietarios de las tierras y casas de la villa, los cuales, por otra parte, comprueban cómo "no hay quien quiera entrar al cultivo de ellas aunque se las den sin interés" mientras no se libere a sus moradores de impuestos ${ }^{57}$. En este año, el lugar de Ruyales del Páramo, en Burgos, despoblado desde 1681 - sólo reside un criado del licenciado José de Palacio Escalante, su titular-, consigue también exención fiscal de todos sus tributos exceptuado el servicio de millones, ya que, según expone el Consejo de Hacienda, es un derecho que abonan los consumidores aun

${ }^{52}$ AGS, CJH, leg. 1.495. Consulta del Consejo de Hacienda, 26 de enero de 1685.

${ }^{53}$ KAMEN, H., obra citada, pág. 162.

${ }^{54}$ AGS, CJH, leg. 1.541. Consulta del Consejo de Hacienda, 16 de enero de 1688.

${ }_{55} \mathrm{Ibidem}$, leg. 1.538. Consulta del Consejo de Hacienda, 4 de mayo de 1689; legajos 1.606 y 1.607. Consultas de 22 de septiembre de 1692 y de 6 de julio de 1692.

${ }^{56}$ Ibidem, leg. 1.666. Consultas del Consejo de Hacienda, legs. 12 de junio y 12 de septiembre de 1697.

${ }^{57}$ ibidem, leg. 1.678. Consulta del Consejo de Hacienda, 25 de septiembre de 1698. Veinte años antes tenía 21 vecinos y en 1693 sólo 11 , de los cuales siete eran pobres de solemnidad. En esta fecha se le remite parte de sus deudas y se le modera su encabezamiento de alcabalas, cientos y servicio real a la mitad. 
cuando sean forasteros, y si no se cobra en el lugar sus vecinos podrán llevar a él "muy considerables especies sujetas a esta contribución, con que [...] tendrán ganancias por cobrar de ellas los derechos pertenecientes a V. M. y será de mucho perjuicio y de muy mal ejemplar" ${ }^{58}$. En 1699, por último, Matamonteagudo, en León, queda eximida del pago de sus cientos durante diez años - las alcabalas pertenecen a la villa-, en atención a su corta vecindad, compuesta de cuatro vecinos ${ }^{59}$.

Es posible que la política repobladora de Carlos II, centrada en la concesión de franquicias fiscales, no favoreciese el crecimiento rápido de los lugares tanto como el reparto de tierras y la distribución de ganados, pero ciertamente lo contrario tampoco hubiese dado los frutos deseados. Por este motivo, cuando en la década de los setenta la Corona se plantea traer artesanos europeos a Castilla, los medios propuestos para facilitar dicha empresa se circunscriben a dos planos complementarios: dispensa de tributos y ayudas económicas en la compra de materias primas y de utensilios. El 23 de diciembre de 1676, el duque de Villahermosa, en carta escrita desde Bruselas, en respuesta a un despacho secreto recibido el 30 de noviembre, así lo aconseja al afirmar que de poco servirá la contratación de maestros holandeses e ingleses si paralelamente el Estado no protege el consumo de sus manufacturas y no las incentiva con privilegios, pues "asentados estos principios conseguiremos que de todas artes se conviden muchas personas al pasaje y residencia en los dominios de Vuestra Majestad" ${ }^{60}$. En 1687, Salazar y Castro abundará en lo mismo: "Tráiganse maestros, anímense con privilegios y encárguese al cuerpo de cada ciudad el progreso de su manufactura" ${ }^{61}$. Con esta política no se pretende únicamente actualizar y mejorar nuestras técnicas para remontar la crisis industrial que se viene padeciendo desde el último cuarto del siglo XVI, sino incrementar a la vez la población del Reino. En este sentido se manifiesta en 1681 Juan de Arizmendi: la ausencia de una industria vigorosa y competitiva ocasiona "muchos menos vasallos $[\ldots]$ Se ven muchas villas y ciudades despobladas y arrui-

58 Ibidem, leg. 1.679. Consulta del Consejo de Hacienda en Sala de Millones, 22 de mayo de 1698, y Consulta del Consejo de Hacienda, 17 de marzo de 1698.

59 Ibidem, leg. 1.694. Consulta del Consejo de Hacienda, 22 de diciembre de 1699.

60 Ibidem, leg. 1.368. Copia de la carta escrita por el duque de Villahermosa en Bruselas, a 23 de diciembre de $1676[\ldots]$ y que se remite al Consejo de Hacienda con fecha de 31 de enero de 1677.

61 Salazar y CAStro, L., "Discurso Político sobre la flaqueza de la Monarquía española en el reinado de Carlos Segundo y valimiento del conde de Oropesa. Año 1687", publicado por Valladares de Sotomayor en Semanario Erudito. Madrid 1787, págs. 129-144. La cita, en la página 143. 
nadas, muchas haciendas perdidas y muchos ánimos postrados, y en lo común y en lo general es todo un llanto" ${ }^{62}$.

Entre 1680 y 1691 se instalan en Castilla diversos artífices, en su mayoría de origen flamenco e italiano, seguidos de franceses $y$, en menor escala, de ingleses, especializados en la manufactura de géneros textiles y de artículos de lujo - se quiere frenar así las importaciones y equilibrar la balanza comercial, muy desfavorable-, y en la fabricación de cordeles, jarcias y lonas. En 1680 se establece en San Martin de Valdeiglesias una fábrica de vidrios y cristales, cuya azarosa vida se prolongará hasta finales de la centuria ${ }^{63}$. En 1684, Claudio Berter aparece en Sevilla ocupado en diferentes actividades relacionadas con el acabado de los tejidos, mientras en Galicia Adrián Roo y Baltasar Kiel, tras introducir el cultivo del lino, firmemente asentado en 1698, según refiere el embajador veneciano, obtienen en 1698 un asiento para confeccionar lienzos y manteles, completando con ello su actividad industrial centrada hasta entonces en la fabricación de jarcias y lonas para la Armada ${ }^{64}$. En 1686, Hubert Marechal, procedente de Hainault, instala en Cuenca una fábrica de tejidos de lana que en 1691 contaba ya con quince telares y en 1700 con veintidós, para alcanzar los sesenta y seis en $1727^{65}$. En 1687, Andres Cool obtiene licencia para fabricar pipas de fumar similares a las que se importan de los Paises Bajos - se obliga a reducir su precio de venta y a enseñar el oficio a los españoles-, y José María de Manso Castelo, genovés, para establecer una fábrica de jabón de piedra en

62 De ARIZMENDI, J., Breve compendio de las sabidas verdades donde se descubren las principales causas de minorarse las Reales rentas y los remedios que se pueden aplicar, Cádiz 1682, fol. 4. Ver también, Alvarez Osorio y REDIN. M., Defensa, unión y restauración de esta Monarquia, con abundantes medios, suaves y ciertos para único remedio de esta Corona y definiciones eficaces del comercio universal de frutos y fábricas de todos los Reinos... BNM, Ms. 6659, fol. 6.

63 AHN, Consejos, leg. 7.190. Consulta del 22 de febrero de 1680; leg. 7.190. Consulta de la Junta de Comercio, 2 de marzo de 1686. Para más datos, Rodriguez García, J., "Algunas noticias sobre una fábrica de vidrio de Venecia en San Martín de Valdeiglesias (1679-1689)", Espacio, Tiempo y Forma, serie IV, 2, Madrid 1989, págs. 155-174.

64 AHN, Consejos, lib. 1.513. Real Cédula de 16 de septiembre de 1688; Garzon PaREJA, M., La Hacienda de Carlos II. Madrid, 1980, pág. 135; Relazioni degli Ambasciatori veneti al Senato, Spagna, vol. X. Turín, 1979, pág. 643; AGS, CJH, leg. 1.528. Consulta de la Junta de Comercio, 5 de octubre de 1688.

Para un estudio de la industria textil coruñesa, ver MEIJIDE PARDo, A., «Aportación a la historia industrial coruñesa. La fábrica textil de Sada (1675-1762)", Revista del Instituto José Cornide de Estudios Coruñeses, I, núm. 1, La Coruña (1965), págs. 77-126, y EnCISO RECIO, L. M., Los establecimientos industriales españoles en el siglo XVIII. La mantelería de La Coruña. Valladolid 1963.

65 Larruga, E., Memorias políticas y económicas sobre los frutos, comercio, fábricas y minas de España. Madrid, 1787-1800, t. XIX, págs. 1-23; Relazioni degli Ambasciatori..., pág. 644; KAMEN, H., obra citada, pág. 130. 
Málaga ${ }^{66}$. En este año, es el español Pedro García de Heredia quien contrata a un franco-navarro, Juan de Cauhape, con el propósito de montar unos telares de bayetas en Sigüenza, a los que incorpora en 1688 veintidós obreros con el beneplácito del obispo de la diócesis. En 1690. Juan Bautista Turón, animado por Cauhape, instala una fábrica en la ciudad y otra en Cifuentes, y en 1692 los hermanos Bernard y Pierre Solance proyectan hacer lo mismo ${ }^{67}$. En 1693 el súbdito francés Juan Trebulet consigue autorización para instalar seis telares de confección de medias de seda ${ }^{68}$.

Muchos otros ejemplos podriamos reseñar pero sobrepasarían los fines de este trabajo. Baste decir que en todos estos casos y en aquellos en que los españoles deciden renovar a sus expensas las técnicas industriales, la Corona, además de anticipar el dinero necesario para el traslado de artífices extranjeros y de proveerles de locales adecuados - a Hebert Marechal, por ejemplo, se le permite utilizar la Casa de Moneda de Cuenca para instalar en ella sus telares-, les autoriza adquirir la materia prima que requieren y los alimentos de sus obreros francos de impuestos, y les concede el privilegio de vender sus manufacturas sin tener que abonar los derechos de alcabalas y cientos. Como el soberano recomienda a la Junta de Comercio en 1688, es primordial asistirles en lo necesario para que la miseria no "los arroje otra vez de estos reinos y se malogre el intento de labrarse en ellos todo género de telas" ${ }^{69}$. La promulgación en 1683 de una Real Cédula por la cual se prohíbe los embargos de telares, tornos y otros utensilios por deudas civiles es también fundamental en esta política de renovación de la industria castellana $^{70}$.

${ }^{66}$ AGS, CJH, leg. 1.514. Consulta del Consejo de Hacienda, 4 de noviembre de 1687 sobre consulta de la Junta de Comercio de 14 de octubre de 1687.

${ }_{67}$ AHN, Consejo, leg. 7.223; LaRRuga, E., obra citada, t. XVI, págs. 180-196; Kamen, H., Ibidem, pág. 130.

${ }^{58}$ AGS, CJM, leg. 1.614. Reales Decretos de 21 de septiembre de 1692 y 3 de julio de 1693. La presencia de Juan Trebulet está documentada desde 1677, primero en Valencia y luego en Madrid, donde se enfrenta con el gremio de la seda. En 1694 aparece afincado en Córdoba. Ver, Larauga, E., Historia de la Real y General Junta de Comercio, Moneda y MInas. Madrid 1789, 11 vols. en manuscrito, v. II, págs. 163-171; CoLMEIRO, M., Historia de la Economía Política, t. II, Madrid 1972, págs. 795-96; MOLas Ribalta, P., «Iniciativas textiles en Andalucía (1680-1710)", en Andalucia Moderna. Actas // Coloquios Historia de Andalucia. Córdoba 1983, t. I, pág. 487.

69 AGS, CJH, leg. 1.528. Consulta de la Junta de Comercio, 5 de octubre de 1688. Sobre las franquicias concedidas, ver los ejemplos citados por MOLAS RIBALTA, P., obra citada, y por FORTEA. J. I., "La industria textil en el contexto general de la economía cordobesa entre fines del siglo XVII y principios del XVII: una reactivación fallida", en Andalucia Moderna. Actas /l Coloquios de Historia de Andalucia, t. I, Córdoba 1983, págs 443-465.

${ }^{70}$ AHN, Consejos, lib. 1.474 y 1.513; Novísima Recopilación, ley XVIII, tit. XXXI, lib XI. 
Tales medidas, que por si solas nos permiten comprender el renacimiento de las manufacturas en muchos lugares del Reino, se complementan con varias resoluciones del Consejo de Hacienda cuando los pueblos se ven asolados por epidemias y malas cosechas que paralizan la actividad industrial de sus vecinos sin posibilidad ninguna de hacer frente al pago de los impuestos, provocando el éxodo de esta mano de obra especializada, según se observa en Alcaudete (Jaén), de donde han emigrado a Priego y Granada, quedando en la villa hortelanos y jornaleros, y en Cantalapiedra (Salamanca), que ha visto arruinarse su fábrica de sombreros ${ }^{71}$. Por esta causa se le perdona a Fuensalida (Toledo) en 1685 la mitad de sus débitos y se le baja el valor de su encabezamiento en un tercio, máxime cuando ahoy sólo han quedado cinco telares de ciento y cincuenta que tenía, en que labraba damascos y otras telas de seda" ${ }^{72}$. El mismo alivio obtiene Astudillo (Burgos) en 1687 para que con él se apliquen sus vecinos «a la restitución de la fábrica de paños en que se ejercitaba en el pasado" ${ }^{73}$. En 1690, Bonilla de la Sierra y su jurisdicción (Ávila) consiguen el perdón de parte de sus deudas, la facultad de tomar a censo 30.000 reales y la baja del 25 por 100 de sus alcabalas durante dos años por no poder "continuar con la fábrica de paños que era el trato que los mantenía y con el que se sustentaban todos los oficiales que entendían en esta manufactura [...], de que se ha seguido el ausentarse muchos y ídose a trabajar a otra parte, y que ha llegado esto a tan miserable estado que se ha cerrado el batán que habia para los paños y el tinte para teñirlos" ${ }^{74}$. En 1692, Castromocho (Valladolid) se beneficia del perdón del 33 por 100 de sus alcances para con-

7 AGS, Cont. Gles., leg. 753. Memorial de Alcaudete, 1682; CJH, leg. 1.480. Consulta del Consejo de Hacienda, 13 de septiembre de 1685.

72 Ibidem, CJH, leg. 1.495. Consulta del Consejo de Hacienda, 19 de mayo de 1685. Consigue esta gracia también en dicho año Las Navas del Marqués (Ávila), pues de 53 telares que tenía permanecen activos únicamente 12, estando además "los tintes demolidos" (Ibídem, leg. 1.480. Consulta del Consejo de Hacienda, 7 de agosto de 1685). A mediados del siglo XVIII la industria de Las Navas del Marqués parece haberse recuperado de la crisis de los ochenta, pues en las Respuestas Generales del Catastro de Ensenada aparecen 249 cardadores, 96 tejedores, 10 tundidores, nueve bataneros - trabajan cinco batanes con una producción que representa el 17,5 por 100 del total provincial-, 27 tintoreros -están empleados en 11 tintes con unas ganancias anuales de 4.500 reales-, 6 fabricantes de cardas, 18 tejedores de lienzos y 4 de sayales. Ver: MARTIN Garcia Gonzalo, La industria textil en Ávila durante la etapa final del Antiguo Régimen La Real Fábrica de Algodón, tesis de doctorado inédita leida en la Facultad de Geografia e Historia de la UNED, 1987, págs. 332-365.

73 Ibidem, leg. 1.527. Consulta del Consejo de Hacienda, 10 de marzo de 1687.

74 Ibídem, leg. 1.572. Consulta del Consejo de Hacienda, 9 de mayo de 1690. En el siglo XVIII todavía no había logrado recuperarse, ya que en las Respuestas Generales del Catastro de Ensenada no aparecen mencionados bataneros ni tintoreros pero sí cuatro tejedores de lienzos y ocho cardadores. Ver: MARTín GARCiA, G., obra citada, págs. 332-365. 
servar su fábrica de estameñas, muy disminuida por falta de capital, y un año después Brieva, en Burgos, obtiene la baja del 50 por 100 de su encabezamiento por dicho motivo ${ }^{75}$.

Con todo, es preciso indicar, como ya lo hiciera J. I. Fortea respecto de Córdoba, que el progresivo desmantelamiento de las nuevas manufacturas a partir de 1691 no tuvo su origen en el desinterés del Estado ni en la escasez de dinero para sufragar estas empresas, sino en la dificultad que encontraban los fabricantes -esto es aplicable también a las fábricas antiguas- en introducir su producción en el mercado, pues la mayoría de los comerciantes prefirió adquirir las manufacturas elaboradas fuera de nuestras fronteras, al margen de su calidad y mejor precio, porque asi escapaban del control fiscal y duplicaban o triplicaban sus beneficios. Actuando de este modo, expone la Junta de Comercio en 1688 , "no se les puede averiguar la costa que les tienen en la compra para arreglárselos por ella a la venta y a la utilidad proporcionada que respectivamente les debe corresponder ${ }^{76}$. Las consecuencias de esta actitud de los mercaderes castellanos, guiada por el lucro y por los intereses comerciales extranjeros que a menudo representaban, explica que en 1692 el Consejo de Castilla trate de impedir la fuga de artesanos hacia Portugal donde se les ofrecen mejores condiciones, prohibiendo los cambios de residencia sin la debida autorización de las justicias locales ${ }^{77}$. Una medida a todas luces inoperante, pues en torno a 1700 continuaba agonizando nuestra ya decaída industria textil y a duras penas sobrevivian las fábricas y telares instalados en la década de los ochenta bajo la dirección de artífices europeos venidos a Castilla con el propósito de renovar las técnicas y hacer más competitivas las manufacturas nacionales; un objetivo laudable aunque por desagracia de escasos resultados y que tal vez - pero sólo tal vez- una política proteccionista firme hubiese logrado consolidar.

De la lectura de estas páginas se desprende una conclusión obvia: en contraste con el siglo XVIII no existió en el reinado de Carlos II un proyecto

75 Ibídem, leg. 1.607. Consulta del Consejo de Hacienda, 30 de julio de 1692, y leg 1.621. Consultas de 22 de junio y 7 de julio de 1693.

76 Ibídem, leg. 1.528. Consulta de la Junta de Comercio, 29 de octubre de 1688. Denuncian esta situación FORTEA, J. I., La industria textil..., pág. 457, y KAMEN. H., obra citada, página 132.

7 AHN, Consejos, lib. 1.474. Real Cédula de 12 de noviembre de 1692; leg. 7.205. Consulta del Consejo de Castilla, 3 de noviembre de 1692. 
bien definido por parte de la Corona para repoblar el Reino, aunque en 1678 se sabe de varias propuestas con estas miras, como, por ejemplo, la de establecer una colonia procedente de Esparta y que fue rechazada por el Consejo de Castilla argumentando que había población suficiente para cubrir las zonas deshabitadas ${ }^{78}$. Aun así, la moderación de los impuestos y las rebajas concedidas a los pueblos en sus encabezamientos y deudas coadyuvan a su alivio y, en definitiva, favorecen los matrimonios y el incremento de la natalidad, objetivo prioritario en estos años finales del siglo. Por lo mismo que se fomente también la venida de artesanos extranjeros y se aliente a los empresarios nacionales con exenciones tributarias y ayudas económicas. Quizá estos medios no resulten a primera vista tan espectaculares como los adoptados por los Borbones y concretamente por Carlos III, pero pensamos que a largo plazo aseguraban el crecimiento demográfico del Reino y, por tanto, la repoblación de los lugares, y ello en un momento en que, pese a los estragos de todo tipo que se produjeron entre 1676 y 1685 , se habian invertido ya los signos fatales de la decadencia y la población comenzaba a aumentar con renovada esperanza en su futuro, no obstante el pesimismo de muchos contemporáneos para quienes todavía no estaban asentadas las bases del progreso económico de Castilla.

${ }^{78}$ Ibídem, leg. 7.188. Consulta del Consejo de Castilla, 23 de marzo de 1678. 